\title{
PUMPING OF HYDROCARBONS USING
}

\section{NON-EVAPORABLE GETTERS}

\author{
L. C. Emerson ${ }^{a)}$, R. J. Knize, and J. L. Cecch1 \\ Plasma Physics Laboratory, Princeton University \\ P.0. Box 451 \\ Princeton, NJ 08544
}

Pumping speed measurements have been obtained for a number of gaseous hydrocarbons including members of the alkene, alkadiene, and cycloalkane groups as a function of temperature using a $\mathrm{Zr}-\mathrm{Al}$ alloy getter. Pumping speeds were obtained by analysis of an exponential least squares fit to the pressure decay curve following introduction of each gas. It was found that these pumping speeds are relatively high (up to $400 \mathrm{l} / \mathrm{s}$ ) and exhibit, with only a few exceptions, little temperature dependence. This is in contrast to the earlier reported results for the alkane series.

\section{i DISCLAIMER}

This report was prepared as an account of work sponsored by an agency of the United States Government. Neither the United States Government nor any agency thereof, nor any of their employees, makes any warranty, express or implied, or assumes any legal liability or responsibility for the accuracy, completeness, or usefulness of any information, apparatus, product, or process disclosed, or represents that its use would not infringe privately owned rights. Reference herein to any specific commercial product, precess, or service by trade name, trademark, manufacturer, or otherwise does not necessarily constitute or imply its endorsement, recommendation, or favoring by the United States Government or any agency thereof. The views and opinions of authors expressed herein do not necessarily state or reflect those of the United States Government or any agency thereof.

\section{MASTER}

By acceptance of this article, the publisher or recipient acknowleuges the U.S. Government's right to retain a nonexclusive, rovalty-frae licente in and to any copvright covering the article. 


\section{INTRODUCTION}

The high pumping speeds for many common gases combined with a small physical size has made $\mathrm{Zr}-\mathrm{Al}$ non-evaporable getter pumps useful in a wide variety of vacuum applications. Their high hydrogenic pumping speed and the unusual ability to recover the pumped hydrogen by thermal desorption has made them a popular cholce for a number of fusion devices including TFTR, ${ }^{1}$ PDX, ${ }^{2}$ ISX-B, ${ }^{3}$ and JT-60.4 Hydrocarbons are common impurities in such devices and must be removed to provide the clean environment necessary for successful operation.

We previously considered the dissociative pumping of hydrocarbons by $\mathrm{Zr}-\mathrm{Al}$ resulting from the thermal cracking of molecular chemical bonds on the getter surface, a process responsible for the temperature dependence of the pumping speed. The results for the gaseous members of the alkane series $\left(\mathrm{C}_{\mathrm{n}} \mathrm{H}_{2 \mathrm{n}+2}\right)$ were published previously.5 In this paper we extend this investigation to other hydrocarbons including members of the alkene group; ethylene, $\mathrm{C}_{2} \mathrm{H}_{4}$; propylene, $\mathrm{C}_{3} \mathrm{H}_{6} ; 1$-butene, $\mathrm{C}_{4} \mathrm{H}_{8} ;$ its isomer-1sobutylene; a member of the alkadiene group; $1-3$ butadiene, $\mathrm{C}_{4} \mathrm{H}_{6}$; one of the cycloalkanes; cyclopropane, $\left(\mathrm{CH}_{2}\right)_{3}$; plus one of the alkane isomers; isobutane, $\mathrm{C}_{4} \mathrm{H}_{10}$. The measurements were carried out over a temperature range between 85 and $645^{\circ} \mathrm{C}$. The experimental apparatus and procedures are described in Sect. II. The results are presented and discussed in Sect. III with a summary following in sect. IV.

\section{EXPERIMENTAL APPARATUS AND PROCEDURES}

All of the measurements were carried out using a standard Zr-Al pumping element, S.A.E.S. Model St101-WP1250.6 The pumping module was mounted in the apparatus shown schematically in Fig. 1. The measurement procedure has been previously described and will only be briefly discussed here. 5

Prior to the measurements the entire vacuum system, including the gas manifold, was baked to $200^{\circ} \mathrm{C}$ for a time sufficient to provide a base 
pressure in the low $10^{-9}$ Torr range. The getter element was then activated by resistive heating to $650^{\circ} \mathrm{C}$ for $30 \mathrm{~min}$. Chromel-Alumel thermocouples, spot welded to various points on the getter element, were used to average the 10-15\% variation in temperature over the getter surface.

Just prior to each measurement the getter element temperature was again raised to diffuse any accumulated impurities into the bulk of the alloy to provide a uniformly clean surface for each pumping speed measurement. Following temperature stabilization of the getter the chamber was 1solated from the main pumping system providing a static pressure environment of known volume. Gas of Instrument Purity Grade or higher ( $99.5 \%$ minimum) obtained from Matheson Gas Products ${ }^{7}$ was introduced via a piezoelectric valve in a short burst of 20-30 ms. Immediately following introduction of gas the chamber pressure typically rose to the $10^{-5}-10^{-4}$ Torr range. After this initial increase the fall in pressure due to getter pumping was monitored by measuring the ion collector current from a BayardAlpert type ion gauge using a fast operational amplifier and a transient recorder. Five hundred data points were recorded spaced by the computer system clock to cover $5-6$ vacuum system time constants to ensure that the data were collected well into the tail of the pressure decay curve. Subsequently, these data were fitted by a simple exponential least squares procedure from which the pumping speed was extracted. The model presented in Ref. 5 predicts a slight deviation from a simple exponential due to temperature dependence of the molecular velocity, but for the purpose of this experiment a single exponential is adequate.

\section{RESULTS AND DISCUSSION}

A typical set of measurements is presented in Fig. 2 which shows the raw data for isobutane along with the exponential least squares fit to these data. The experimental errors associated with the measurements are estimated at $10-20 \%$. For comparison the earlier results for the alkane series are presented in Fig. 3. Isobutane is a "pseudo" member of this group as it is an isomeric form of n-butane and may be expected to exhibit generally similar properties. 
Analyzed data for all of the hydrocarbons studied are presented in Fig. 4. The solid lines representing the least squares fits are shown only over the temperature range at which data were obtained for each of the gases. The pumping speeds are seen to fall into three general groups exhibiting widely different values of speeds and temperature dependencies. The gases for which the $\mathrm{Zr}-\mathrm{Al}$ pumping speeds are the highest and which exhibit the least temperature dependence are those from the alkene group; ethylene, propylene, and 1-butene and the single isomer from this group, isobutylene. The one gas from the alkadiene group also exhibits similar properties. Contrasting properties, i.e. low speeds and a large temperature dependence is noted for the single isomer from the alkane group, isobutane. Cyclopropane, a member of the cycloalkanes, exhibits properties intermediate to these two groups.

The high pumping speeds for the alkenes and alkadienes as well as for the common active gases $\left(\mathrm{H}_{2}, \mathrm{~N}_{2}, \mathrm{O}_{2}, \mathrm{H}_{2} \mathrm{O}, \mathrm{CO}, \mathrm{CO}_{2}\right)$ relative to that for the alkanes suggest that $\mathrm{Zr}-\mathrm{Al}$ alloy pumps could be used to selectively pump gases of the former groups from the alkane hydrocarbons thus increasing their purity. This would be especially pronounced at the lower temperatures where the pumping speed differential is greatest.

\section{A. The isoalkanes}

The characteristics of isobutane are generaliy similar to those reported earlier for n-butane, a member of the alkane series. As can be seen by comparing Figs. 2 and 3, at high temperatures the pumping speeds are the same, but at low temperatures the speed for n-butane exceeds that for isobutane by a factor of three. This similarity is not too surprising as the two molecules have the same composition and might be expected to exhibit similar bonding characteristics leading to similar dissociative pumping characteristics. They are related by isomerism in which two compounds possess identical compositions (in th.ls case, $\mathrm{C}_{4} \mathrm{H}_{10}$ ) but a somewhat different structure. n-butane is a chain molecule whereas isobutane has two methyl radicals branched from one of the remaining carbon atoms. However, in both cases all of the valences are saturated and all bonds in the molecules are sigma bonds. The resulting low chemical activity exhibited by these molecules is manifested in their low pumping speeds by $\mathrm{Zr}-\mathrm{Al}$ except at the higher temperatures. 


\section{B. The alkenes and alkadienes}

The alkene group, also consisting of only carbon and hydrogen, is characterized by having two carbon atoms linked together with a double bond and, therefore, two carbon atoms are "unsaturated" with respect to their normal valence capabilities. Each double bond consists of one sigma bond and one pi bond. The alkadiene group is similar, but has two double bonds linking the carbon atoms. Although the bond energy of the carboncarbon double bond is higher than that of the carbon-carbon single bond ( 146 vs $83 \mathrm{kcal}$ ) the two electrons comprising the $\mathrm{p} 1$ bond are not as tightly bound and are more readily available for additive chemical reactions. Thus the alkenes and alkadienes are much more chemically reactive than are the alkanes and exhibit the characteristically higher pumping speeds and lower temperature dependencies.

C. The cycloalkanes

These hydrocarbons are compounds in which the carbon atoms are arranged in a ring form, as opposed to the other group's chain-like structure. The simplest of these is a compound with three carbon atoms, cyclopropane, the results for which are reported here. This group is 1someric with the unsaturated hydrocarbons with one double bond. Their stability lies between that of the alkane and alkene groups. As seen In Fig. 4, cyclopropane exhibits pumping speed and temperature dependence characteristics lying between the other two groups.

\section{The alkynes}

This hydrocarbon group, although not as common as the others, is of interest as their members contain a single carbon-carbon triple bond consisting of one sigma bond and two pl bonds. The bond energy is high (196 kcal) but two of the three electron pairs, being less tightly bound, are more available for chemical activity with the result that these hydrocarbons are very reactive chemically. Acetylene $\left(\mathrm{C}_{2} \mathrm{H}_{2}\right)$ is the most common member of this group. Although not included in this investigation this gas would be expected to be pumped by $\mathrm{Zr}-\mathrm{Al}$ with an even greater 8 peed. 
IV. SUMMARY

Pumplng s:eeds for the hydrocarbons ethylene $\left(\mathrm{C}_{2} \mathrm{H}_{4}\right)$, propylene $\left(\mathrm{C}_{3} \mathrm{H}_{6}\right)$, 1-butf.ae $\left(\mathrm{C}_{4} \mathrm{H}_{8}\right)$, isobutylene $\left(\mathrm{C}_{4} \mathrm{H}_{8}\right), 1-3$ butadiene $\left(\mathrm{C}_{4} \mathrm{H}_{6}\right)$, cyclopropane $\left(\left(\mathrm{CH}_{2}\right)_{3}\right)$, and isobutane $\left(\mathrm{C}_{4} \mathrm{H}_{10}\right)$ have been measured for $\mathrm{Zr}-\mathrm{Al}$ alloy pumps over a range of temperatures from 85 to $645^{\circ} \mathrm{C}$. The pumping speeds for the alkenes and alkadienes are much higher than that of the alkanes including the isoalkanes and they exhibit much less temperature dependence. The cycloalkanes have characteristics which lie between those of the other two groups.

\section{ACKNOWLEDGMENTS}

We would like to thank E. Pinelli and F. Egan for technical support and E. Yu for programming assistance. This work was supported jointly by the U.S. Department of Energy contract DE-ACO2-76-CHO-3073, and Office of Fusion Energy, under contract DE-AC05-84 OR21400 with Martin Marietta Energy Systems, Inc. 


\section{REFERENCES}

a) Permanent address: Oak Ridge National Laboratory, Oak Ridge, TN 37831.

1. J. L. Cecchi et al., J. Nuc1. Mater. 128\&129, 1 (1984).

2. J. L. Cecch1, R. J. Knize, H. F. Dy11a, R. J. Fonck, D. K. Owens, and J. J. Sredniawski, J. Nuc1. Mater. 111\&112, 305 (1982).

3. P. K. Mioduszewski et al., J. Nuci. Mater. 121\&122, 285 (1984).

4. H. Kishimoto et al,, to be published, J. Nucl. Mater.

5. L. C. Emerson, R. J. Knize, J. L. Cecchi, and 0. Auciello, J. Vac. Sci. Technol. A4, 297 (1986).

6. Società Apparechi Eletricle e Scientificl, Milan, Ital j/

7. Matheson Gas Products, East Rutherford, NJ 07073. 


\section{FIGURE CAPTIONS}

1. Schematic diagram of the experimental apparatus.

2. Measured pumping speed for isobutane as a function of tempera:ure. The solid line is an exponential least squares fit to the data points.

3. Pumping speeds for the alkanes as a function of temperature as reported In Ref. 5 .

4. Measured pumping speeds for the gaseous hydrocarbons as a function of temperature. The solid lines represent the exponential least squares fit to the data over the temperature range studied for each gas. 